\title{
The Evaluation of use of Complementary and Alternative Medicine Practices in the Treatment of Children with Chronic Neurological Disease
}

\author{
Kürşat Bora Çarman 1, Sibel Laçinel Gürlevik', Emre Kaplan1, (1) Meltem Dinleyici², \\ Coşkun Yarar ${ }^{1}$, (i) Didem Arslantaş 3
}

${ }^{1}$ Department of Pediatric Neurology, Eskisehir Osmangazi University Faculty of Medicine, Eskisehir, Turkey

${ }^{2}$ Department of Social Pediatrics, Eskisehir Osmangazi University Faculty of Medicine, Eskisehir, Turkey

${ }^{3}$ Department of Public Health, Eskisehir Osmangazi University, Faculty of Medicine, Eskisehir, Turkey

\begin{abstract}
Introduction: The aim of present study was to search the use of complementary and alternative medicine practices in children with chronic neurological disorders and associated factors.

Methods: The prepared questionnaire was applied to parents of children admitted to the pediatric child neurology unit. Results: A total of 832 parents participated in the search. Twenty-five per cent of parents stated that they had been using complementary and alternative medicine for the treatment of their children over the past year. It has been found that the incidence of complementary and alternative medicine increases with increasing maternal education level and income level of the family. The religious methods were most frequent modality. Only 5.8\% of parents informed their doctors who managed follow-up and treatment

Discussion and Conclusion: One of every 4 children is using complementary and alternative medicine practices. Considering the possible side effects, we think that this question should be asked during routine visits to the outpatient clinic and pediatricians.

Keywords: Children; chronic; complementary and traditional medicine; neurologic.
\end{abstract}

C omplementary and alternative medicine (CAM) applications define a set of treatments in addition to or in place of basic medical treatment. Herbal products, acupuncture, honey, bioenergy, diet, homeopathy, massage and religious methods are the main CAM applications ${ }^{[1]}$. The frequency of CAM usage is increasing worldwide ${ }^{[2]}$. Childhood diseases have been also used in CAM applications ${ }^{[2,3]}$. Orhan et al. ${ }^{[4]}$ found that the incidence of CAM use among our country children increased from $38 \%$ to
49\%. Complementary and alternative medicine applications can be used in the treatment of chronic diseases ${ }^{[5-8]}$. The frequency of use of CAM among children with neurological complaints has been reported at incidence rates ranging from 13 to $78 \%[7,9]$. Complementary and alternative medical practices may cause side effects, just as modern treatment methods ${ }^{[10]}$. For this reason, it is vital for patients using CAM practices to share follow-up and treatment plans with their doctors. However, investigations have determined

Correspondence (İletişim): Kürşat Bora Çarman, M.D. Department of Pediatric Neurology, Eskisehir Osmangazi University Faculty of Medicine, Eskisehir, Turkey

Phone (Telefon): +90 2222390278 E-mail (E-posta): kbcarman@gmail.com

Submitted Date (Başvuru Tarihi): 08.03.2018 Accepted Date (Kabul Tarihi): 19.03.2018

Copyright 2018 Haydarpaşa Numune Medical Journal

This is an open access article under the CC BY-NC license (http://creativecommons.org/licenses/by-nc/4.0/). 
that many patients do not have this information ${ }^{[9-11] . ~}$ In the light of these information, in this study, we evaluated the frequency of use of complementary and alternative medicine in children with chronic neurological complaints who were followed up and treated in pediatric neurology clinic.

\section{Materials and Methods}

This study was conducted by face-to-face interviews with the parents of the patients who applied to the pediatric neurology clinic between March 2017-June 2017. The questionnaire consisted of three parts. In the first part, the sociodemographic characteristics of the parents and the child were questioned and in the second part, the information about the medical condition of the child who was followed up and treated was tried to be obtained.

The final part of the questionnaire was designed to question parents' attitudes about complementary and traditional medical practice and their applications for the treatment of sick children. Statistical analyzes were performed using the Statistical Package for Social Sciences Program (SPSS) 13.0 statistical program. Chi-square and Student ttests were used. Smaller results than $p<0.05$ were evaluated statistically. The study was approved by Eskişehir Osmangazi University Ethics Committee.

\section{Results}

A total of 1000 parents were invited to participate in the survey and $832(82.3 \%)$ of them agreed to participate in the survey. The study group consisted of $480(57.7 \%)$ male and

Table 1. Sociodemographic characteristics of the research group

\begin{tabular}{lc}
\hline Characteristics & $\mathbf{n}(\%)$ \\
\hline Gender & \\
$\quad$ Male & $480(57.7)$ \\
$\quad$ Female & $352(42.3)$ \\
Mean age (mean \pm SD) & \\
$\quad$ Male & $38.75 \pm 7.21$ \\
Female & $34.57 \pm 6.11$ \\
Male-Educational level & \\
Primary & $352(42.3)$ \\
Lycée & $272(32.7)$ \\
University & $208(25)$ \\
Female-Educational level & \\
Primary & $560(67.3)$ \\
Lycée & $176(21.3)$ \\
University & $96(11.5)$ \\
Monthly income & \\
$\quad<1500$ TL & $320(38.5)$ \\
1501-3000 TL & $272(32.7)$ \\
30001- 6000 TL & $144(17.3)$ \\
$>6000$ TL & $96(11.5)$ \\
\hline
\end{tabular}

$352(42.3 \%)$ women. The mean age was $38.75 \pm 7.21$ for men and $34.57 \pm 6.11$ years for women. When parents' educational status was assessed, $25 \%$ of the fathers, and only $11.5 \%$ of the mothers were university graduates. Most $(71.2 \%)$ of the respondents stated that their monthly family income was below $3000 \mathrm{TL}$. The sociodemographic characteristics of the research group are listed in Table 1.

The mean age of the children who were followed-up and treated in the pediatric neurology clinic was $8.64 \pm 4.39$ years. While $67.3 \%$ (560) of the sick children were followed and treated with the diagnosis of epilepsy (Table 2).

Most (84.6\%) of the patients were still on medication prescribed for the treatment. Two hundred and eight (25\%) parents who participated in the study stated that they had used complementary and alternative medicine for the treatment of their children within the last year.

There was no correlation between the diagnoses of the patients and the frequency of use of complementary and traditional medical practices ( $p>0.05$ ). Only $5.8 \%$ of the parents using CAM practices reported benefit from the methods they used. When detailed and traditional medical practices were questioned in detail, $69.2 \%$ (576) of the parents stated that they resorted to religious practice. It was found that the most used religious practices were praying and usingt amulets.

Two hundred and eight parents used a herbal treatment regimen for their child. Table 3 contains complementary and traditional medical practices applied by parents to their children.

Table 2. Diagnosis of the patients followed up, and treated in the polyclinic of pediatric neurology

\begin{tabular}{lc}
\hline Diagnosis & $\mathbf{n}(\%)$ \\
\hline Epilepsy & $560(67.3)$ \\
Febrile convulsion & $80(9.6)$ \\
Neuromotordevelopmental delay & $48(5.8)$ \\
Neuromuscular disease & $16(1.9)$ \\
Cerebral palsy & $64(7.7)$ \\
Other & $64(7.7)$ \\
\hline
\end{tabular}

Table 3. Complementary, and traditional medicine practices used by parents for their children

\begin{tabular}{lc}
\hline Applications & $\mathbf{n}(\%)^{*}$ \\
\hline Religious methods (Prayer, amulet) & $576(69.2)$ \\
Herbal & $208(25)$ \\
Acupuncture & $16(1.9)$ \\
Bioenergy & $96(11.5)$ \\
Honey and related products & $272(32.7)$ \\
\hline
\end{tabular}

*Parents might use these applications for their children more than once. 
It was determined that $76 \%$ of the parents using herbal products use these products on the recommendation of their neighbours or another patient, and $27 \%$ of them believed that herbal medicines were natural without side effects. The statistical analysis revealed that the level of maternal education and the monthly income of the family increased as the frequency of complementary and traditional medical practice increased (Table 4 ). Only $5.8 \%$ of the parents stated that they informed their physicians who were performing their follow-up and treatment about their treatment methods that they had been currently practicing.

\section{Discussion}

In Eskişehir, the province where this study was carried out, the incidence of CAM use among adults was determined as $60 \%{ }^{[12]}$. For the treatment of children with chronic neurological disease, the frequency of use of complementary and alternative medicine applications was lower and 25\% was detected in our study. In a survey conducted in our country, this rate was reported as $27.2 \%$. Many studies on children have focused on children with chronic illness or inadequacy.

Mc Cann and Newell found that the frequency of use of CAM in healthy children was $12 \%$, but it increased to $40 \%$ in children with chronic health problems ${ }^{[13]}$. It has been determined that indicated percentages of children with asthma (52\%), attention -deficit hyperactivity disorder $(68 \%)$, cancer $(65 \%)$, or cerebral palsy $(56 \%)$ stated that they had used various CAM practices at least once ${ }^{[14-17] .}$
We conducted our research with children with neurological disease. In a study conducted in the United States, the use frequency of CAM was determined as $12.6 \%$ in healthy children, and in $24 \%$ of those with neurological complaints ${ }^{[7]}$.

There are variety of treatment modalities defined as complementary and alternative medical practices. Most frequently used CAM practice in our study was prayer and use of amulets. Similarly, investigations conducted in Islamic countries, as in our country have demonstrated that most frequently religious applications are being used [18]. In Western countries, the types of practices vary. In the United States, homeopathy-like applications are predominantly practiced, while in Korea, herbal products are more frequently used ${ }^{[8,10]}$.

In our study, one-fourth of the participants were using herbal products and relatives of neighbors or other patients were the most frequently used information source for use of herbal products. In a studyon the frequency of complementary and alternative medical practices in pediatric epilepsy patients in Germany, the Internet was identified as the most frequent source of information among parents ${ }^{[8]}$. It is thought that differences among information sources stem from differences in internet usage habits in countries.

Most complementary and alternative medicine implementations are initiated by parents. For this reason, we realized our survey with parents. While there was no relationship between educational levels of fathers and frequency of CAM use, it was determined that the rate of CAM usage in-

Table 4. The effect of educationallevel of parents, and monthly income of the family on the frequency of CAM use

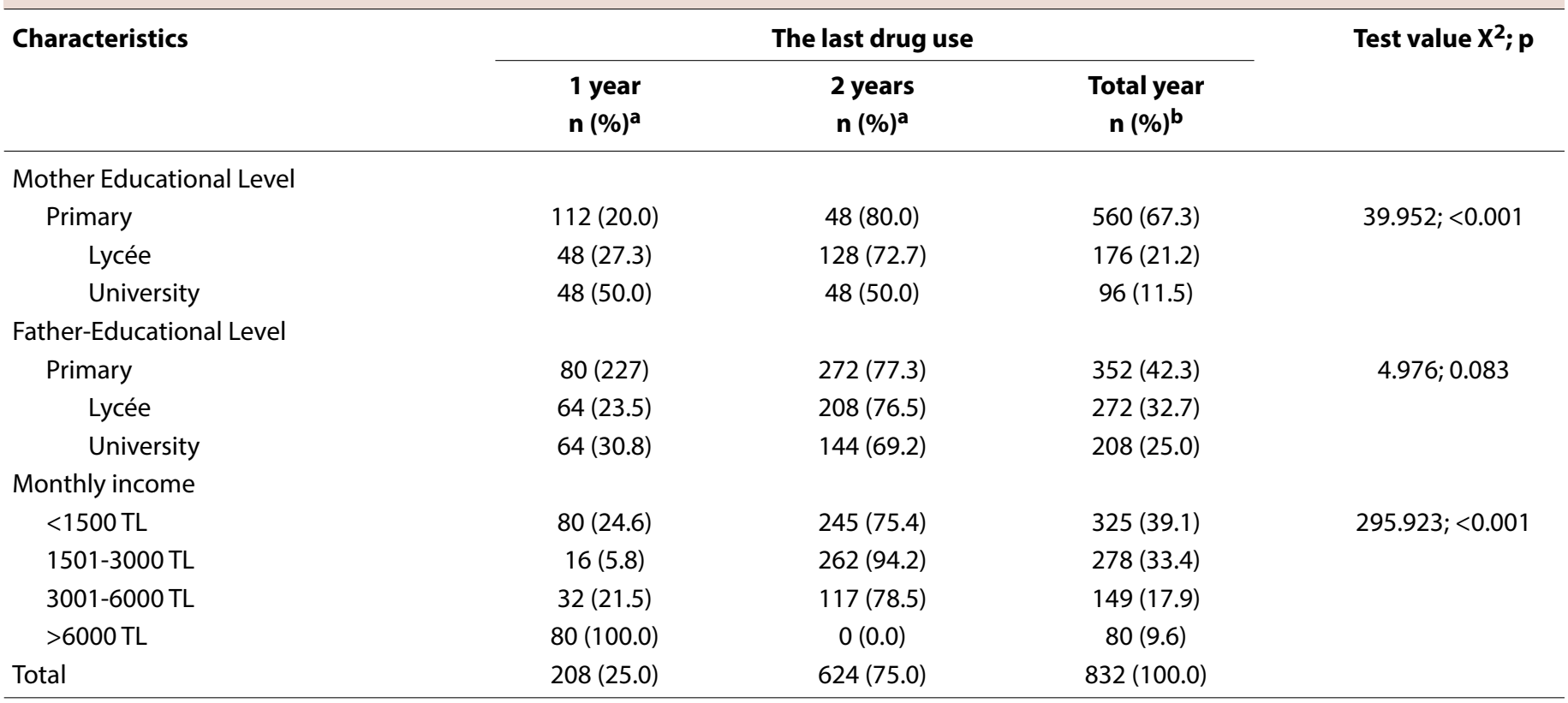


creased as the educational level of mother increased.

Different results have been reached concerning the effects of education levels on parents ${ }^{[18]}$. In a study conducted by Aburahma et al. ${ }^{[19]}$ in a pediatric neurology clinic, frequency of CAM use was reported as $56 \%$, and low maternal education level was an effective factor on the frequency of CAM applications.

In a study conducted in the pediatric neurology clinic, $88.5 \%$ of the parents were found to be university graduates [20]. Similar results were detected in investigations realized in our country. The results of researches in the eastern parts of our country showed that CAM was being used more frequently among people with lower educational levels, whereas in the western provinces contrary results were obtained ${ }^{[21,22]}$. In our study, we found that as the monthly income of the family increases, the frequency of use of CAM increases.

Complementary and alternative medicine applications are not disease but patient-based approaches. We think that it is useful for patients to be informed about the possible side effects of such treatments and to specify the importance of information sharing. For this reason, only $5.8 \%$ of the patients shared their knowledge of CAM usage with the physician who conducted the treatment. In a study conducted in Germany with pediatric epilepsy patients the frequency of CAM was $76 \%{ }^{[8]}$.

Not only patients should share information, but also their physicians who plan and carry out treatment are required to their patients about use of CAM. Beattie et al. ${ }^{[23]}$ reported that $68 \%$ of physicians treating epileptic children were not questioning the use of CAM. As a result; we found that $25 \%$ of children with chronic neurological complaints who were followed up and treated in the pediatric neurology clinic used CAM, but only $5.8 \%$ of their parents shared this information with their physicians.

In consideration of potential side effects during routine polyclinic visits, use of CAM should be also inquired, and pediatricians should be kept this important issue in mind.

Ethics Committee Approval: The study was approved by Eskişehir Osmangazi University Ethics Committee.

Peer-review: Externally peer-reviewed.

Authorship Contributions: Concept: K.B.C., M.D.; Design: K.B.C., D.A.; Data Collection or Processing: S.L.G., E.K., C.Y.; Analysis or Interpretation: D.A.; Literature Search: K.B.C., M.D.; Writing: K.B.C.

Conflict of Interest: None declared.

Financial Disclosure: The authors declared that this study received no financial support.

\section{References}

1. Evaluation of researches about complementary and alternative medicine in children [Article in Turkish]. Çocuk Sağlığı ve Hastalıkları Dergisi 2009;52:183-94.

2. Can B, Akan H, Topaloglu Demir F, Zindanci I, Cebeci F, Turkoglu $Z$, et al. Complementary and Alternative Therapies Used by Patients of Pediatric Dermatology Outpatient Clinics in Turkey: A Multicenter Study. Pediatr Dermatol 2017;34:72-7. [CrossRef]

3. Complementary medicine is booming wolrdwide. BMJ 1996;313:131-3. [CrossRef]

4. Orhan F, Sekerel BE, Kocabas CN, Sackesen C, Adalıoglu G, Tuncer A. Complementary and alternative medicine in children with asthma. Ann Allergy Asthma Immunol 2003;90:611-5.

5. Giangioppo S, Kalaci O, Radhakrishnan A, Fleischer E, Itterman J, Lyttle B, et al. Complementary and alternative medicine use in children with cystic fibrosis. Complement Ther Clin Pract 2016;25:68-74. [CrossRef]

6. Höfer J, Hoffmann F, Bachmann C. Use of complementary and alternative medicine in children and adolescents with autism spectrum disorder: A systematic review. Autism 2017;21:387402. [CrossRef]

7. Treat L, Liesinger J, Ziegenfuss JY, Humeniuk K, Prasad K, Tilburt JC. Patterns of complementary and alternative medicine use in children with common neurological conditions. Glob Adv Health Med 2014;3:18-24. [CrossRef]

8. Hartmann N, Neininger MP, Bernhard MK, Syrbe S, Nickel P, Merkenschlager $A$, et al. Use of complementary and alternative medicine (CAM) by parents in their children and adolescents with epilepsy - Prevelance, predictors and parents' assessment. Eur J Paediatr Neurol 2016;20:11-9. [CrossRef]

9. Soo I, Mah JK, Barlow K, Hamiwka L, Wirrell E. Use of complementary and alternative medical therapies in a pediatric neurology clinic. Can J Neurol Sci 2005;32:524-8. [CrossRef]

10. Yeon GM, Nam SO. The use of complementary and alternative medicine in children with common neurologic diseases. Korean J Pediatr 2016;59:313-8. [CrossRef]

11. Martel D, Bussières JF, Théorêt $Y$, Lebel D, Kish S, Moghrabi A, et al. Use of alternative and complementary therapies in children with cancer. Pediatr Blood Cancer 2005;44:660-8. [CrossRef]

12. Çetin OB. Eskişehir'de tamamlayıcı ve alternatif tıp kullanımı. Sosyoekonomi 2007;2:91-100.

13. McCann LJ, Newell SJ. Survey of paediatric complementary and alternative medicine use in health and chronic illness. Arch Dis Child 2006;91:173-4. [CrossRef]

14. Shenfield G, Lim E, Allen H. Survey of the use of complementary medicines and therapies in children with asthma. J Paediatr Child Health 2002;38:252-7. [CrossRef]

15. Shinha D, Efron D. Complementary and alternative medicine use in children with attention deficit hyperactivity disorder. J Paediatr Child Health 200;41:23-6.

16. Friedman T, Slayton WB, Allen LS, Pollock BH, Dumont-Driscoll $M$, Mehta $P, S$ et al. Use of alternative therapies for children with cancer. Pediatrics 2005;100:E1. [CrossRef]

17. Hurvitz EA, Leonard C, Ayyangar R, Nelson VS. Complemen- 
tary and alternative medicine use in families of children with cerebral palsy. Dev Med Child Neur 2003;45:364-70. [CrossRef]

18. Akins RS, Krakowiak P, Angkustsiri K, Hertz-Picciotto I, Hansen RL. Utilization patterns of conventional and complementary/ alternative treatments in children with autism spectrum disorders and developmental disabilities in a population-based study. J Dev Behav Pediatr 2014;35:1-10. [CrossRef]

19. Aburahma SK, Khader YS, Alzoubi K, Sawalha N. Complementary and alternative medicine use in a pediatric neurology clinic. Complement Ther Clin Pract 2010;16:117-2. [CrossRef]

20. Kenney D, Jenkins S, Youssef P, Kotagal S. Patient Use of Complementary and Alternative Medicines in an Outpatient Pedi- atric Neurology Clinic. Pediatr Neurol 2016;58:48-52.e7.

21. Gözüm S, Tezel A, Koc M. Complementary alternative treatments used by patients with cancer in eastern Turkey. Cancer Nurs 2003;26:230-6. [CrossRef]

22. Yavuz M, İlçe A, Kaymakçı Ş, Bildik G, Dıramalı A. Examination of the complementary and alternative treatment use with breast cancer patients [Article in Turkish]. Turkiye Klinikleri J Med Sci 2007;27:680-6.

23. Beattie JF, Thompson MD, Parks PH, Jacobs RQ, Goyal M. Caregiver-reported religious beliefs and complementary and alternative medicine use among children admitted to an epilepsy monitoring unit. Epilepsy Behav 2017;69:139-46. [CrossRef] 